Pak. j. sci. ind. res. Ser. A: phys. sci. 201558 (3) 142-148

\title{
Downstream Wind Flow Path Diversion and Its Effects on the Performance of Vertical Axis Wind Turbine
}

\author{
Abdul Latif Maganhar ${ }^{\mathrm{a}}$, Altaf Hussain Rajpar*a, Saleem Raza Samo ${ }^{\mathrm{b}}$ and \\ Muhammad Ramzan Luhur \\ ${ }^{a}$ Mechanical Engineering Department, Quaid-e-Awam University of Engineering, \\ Science and Technology, Nawabshah, Pakistan \\ ${ }^{b}$ Energy and Environment Engineering Department, Quaid-e-Awam University of \\ Engineering, Science and Technology, Nawabshah, Pakistan
}

(received April 21, 2014; revised September 29, 2014; accepted October 2, 2014)

\begin{abstract}
In the present experimental study efforts have been made to analyse path diversion effect of downstream wind flow on performance of vertical axis wind turbine (VAWT). For the blockage of downstream wind flow path at various linear displaced positions, a normal erected flat wall, semi-circular and cylindrical shapes were tested for path diverting geometries. Performance of VAWT in terms of improved rotor speed up to $45 \%$ was achieved.
\end{abstract}

Keywords: upstream flow, downstream flow, wind diversion, vertical wall, wind turbine

\section{Introduction}

Urbanisation and industrialisation are two important processes of socio-economic development and are directly dependent on the cheap source of available energy. Due to continuous depletion of fossil fuels resources, focus has been shifted to develop renewable energy resources. Sustainable living is impossible without environmental friendly and depen-dable energy generation processes. Renewable sources energy, like wind and solar are dependable and have the capacity and potential to face future energy challenges. Efficient and economic renewable resource based power generation is now the top priority of researchers.

In low windy or turbulent wind zones, energy generation from wind source by using conventional wind turbines would not be suitable due to high cutting speed of turbine. It require to be integrated with wind concentrating guide techniques as reported by Chong et al. (2011), Lu and Ip (2009) and Oppenheim et al. (2004). Modification in design of ducted or funneled wind turbines suitable for low windy areas to improve the incoming wind speed was proposed by Dhanasekaran and Govardhan (2005). Vane guided mechanism for upstream wind flow for conventional wind turbine and its effects on turbine performance has been reported by Wang et al. (2008) and Grassmann (2003). The study showed that efficiency and starting characteristics of the wells turbine (a ducted turbine) has been improved when compared with the conventional turbines without

*Author for correspondence; E-mail: altafrajpar@yahoo.com guided vanes. Hu and Cheng (2008) integrated a vertical axis wind turbine with vertical bucket shaped duct to guide and concentrate incoming wind flow. It was proved that conventional wind turbine with integrated wind accelerating techniques has increased the flow around the generator and was estimated that the power extraction efficiency can be increased up to $80 \%$ due to proposed ducting effect.

Abe et al. (2005) conducted experimental and analytical investigations on a new diffuser-shrouded wind turbine assembly. The characteristic values of the flow fields were estimated and compared with those for a bare wind turbine. It was concluded that the diffuser-shrouded wind turbine provides much higher power output as compared to the bare wind turbine. The power coefficient of the diffuser-shrouded wind turbine was about four times that of the bare wind turbines. It is also reported that with a simple momentum theory, developed along the lines of momentum theory for bare wind turbines, the power generated is proportional to the mass flow rate generated at the nozzle of the diffuser augmented wind turbine (DAWT) proposed by Bussel (2007). Such mass flow expansion can be achieved through two basic principles i.e. (i) increase in the diffuser exit to inlet area ratio (ii) by decreasing the negative back pressure at the exit.

Generally, urban areas have weak wind conditions and turbulence due to the presence of high rise buildings. The number of obstacles in the path of the wind also makes it difficult to model the wind turbine due to turbulent effect of wind as investigated by Ssu-Yuan and 
Jung-Hu (2008), Webb (2007) and Lawn (2003). Thus, the wind energy generation systems for urban regions need to address turbulent effects. More sources of wind guided mechanisms are required to facilitate these thickly populated low windy regions. Grant and Kelly (2008) have also reported that ducted wind turbine which is attached to the roof of a building has a significant potential for retrofitting onto the existing building with minimum visual impact. Omni-directional-guide-vane (ODGV) turbine was introduced by Chong et al. (2009). It was proposed that the patented design overcomes the inferior aspect of low wind speed by guiding and increasing the speed of high altitude wind through the ODGV. The expected wind speeds and the wind energy potential depends strongly on the local weather conditions and building arrangement. Modeling the flow field in such urban canyons is difficult as stated by Li et al. (2008) and Lilley and Rainbird (1956). A novel shrouded wind solar hybrid renewable energy and rain water harvester with Omni-directional-guide-vane (ODGV) systems for urban high-rise application was introduced by Chong et al. (2012). The ODGV surrounds the vertical axis wind turbine (VAWT) and enhances the VAWT performance by increasing the incoming wind speed and guiding it to an optimum flow angle before it strikes with the rotor blades. The experimental results showed that the rotational speed of the VAWT increases by about 2 times. Numerical studies carried out by Sung-Cheuol and Sueng-Hee (2013) showed that blade profile of VAWT directly affects the performance of the turbine.

From this reviewed study, it was observed that the performance of wind generators working in low windy areas have been improved by concentrating and introducing guide mechanism for upstream wind flow. Efforts have not been taken into consideration to introduce a guide mechanism for downstream wind flow. So far limited research has been carried out to improve the diffuser geometry and its effect on rotor performance. The present study is therefore, an attempt to extract maximum energy from the downstream wind flow by introducing a mechanism to divert the downstream wind flow that may be more beneficial as compared to the conventional outgoing downstream wind flow.

\section{Materials and Methods}

Four bladed Savonius rotor of $1 \mathrm{~m}^{2}$ projected areas with blade size of $0.92 \times 0.46 \mathrm{~m}$ fixed on $0.6 \mathrm{~m}$ tripod stand was developed in workshop of Mechanical Engineering Department of Quaid-e-Awam University Nawabshah, Sindh, Pakistan. Low speed open wind tunnel comprising wind speed controller with exit area of $0.09 \mathrm{~m}^{2}$ was used as an auxiliary wind source as shown in Fig. 1.

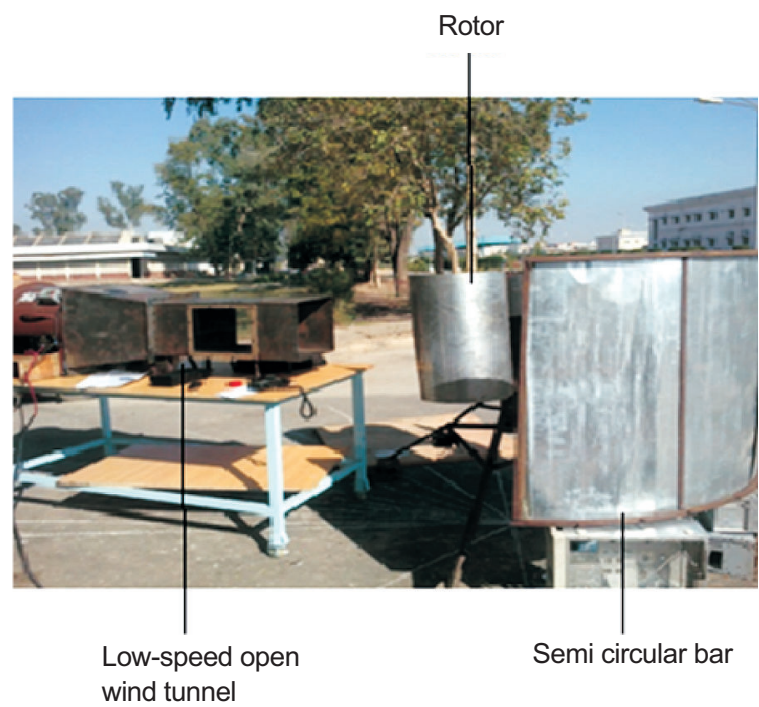

Fig. 1. Over view of developed system.

Test setup. A continuous controlled source of wind was introduced so that (i) minimize the error in analysis (ii) constant source of wind during experimentation. For continuous, constant speed of the wind, a wind tunnel was used as wind source. Average of five tests for each setup was considered for further analysis. Keeping in view the orientation and type of the downstream wind blockage such as flat wall, semi circular vertical wall and cylindrical wall were used as flow diverters as shown in Fig. 2 (a-c).

In this setup four bladed rotor was kept on fixed position and wind source with constant wind beam was adjustable to decide the suitable striking angle of the wind source on the blade starting from origin of the rotor towards the tip of the blade as shown in Fig. 3.

Figure 3 is the plan view of the rotor and wind source. The performance of the rotor in terms of the speed was tested in the absence of any downstream blockage. Initially, the wind at constant speed of $1 \mathrm{~m} / \mathrm{s}$ was introduced by rotating the direction of wind source. In such a way by keeping source wind speed at $3 \mathrm{~m} / \mathrm{s}$ and $5 \mathrm{~m} / \mathrm{s}$, simultaneous tests were conducted so that appropriate angle of wind source can be decided for further data analysis.

Down stream wind blockage. Flat wall wind diverter. A flat wall up to the projected area of the rotor was placed vertically parallel to vertical axis of the rotor at the downstream side. Wind from the source, after hitting the rotor, experienced blockage on the downstream flow and tried to change the path of flow according to the geometry of solid wall, resulting change in rotor speed.

A normally erected flat bar used to block the downstream flow of air was made flexible. Effect of wind blockage on 


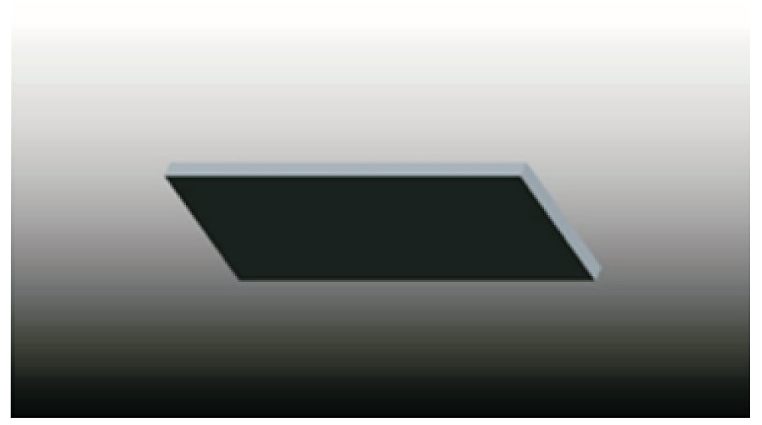

Fig. 2 (a). Flat wall

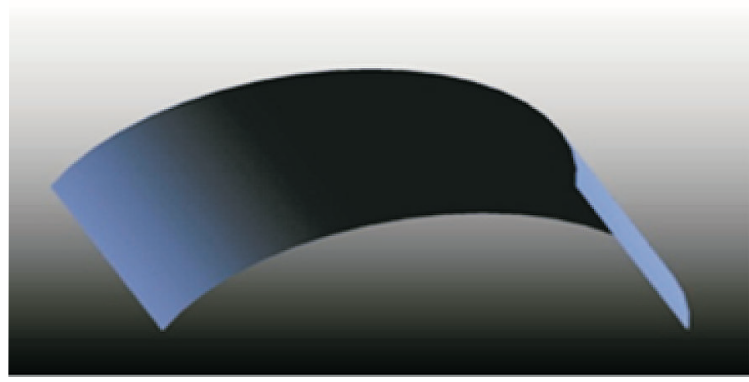

Fig. 2 (b). Semi-circular wall

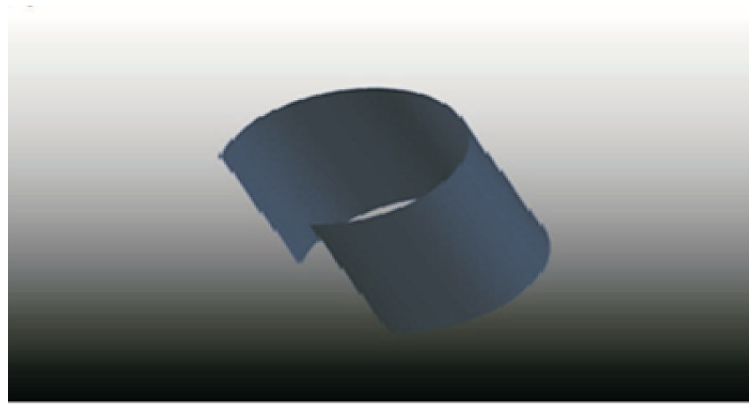

Fig. 2 (c). Circular wall

Fig. 2 (a-c). Types of blockages.

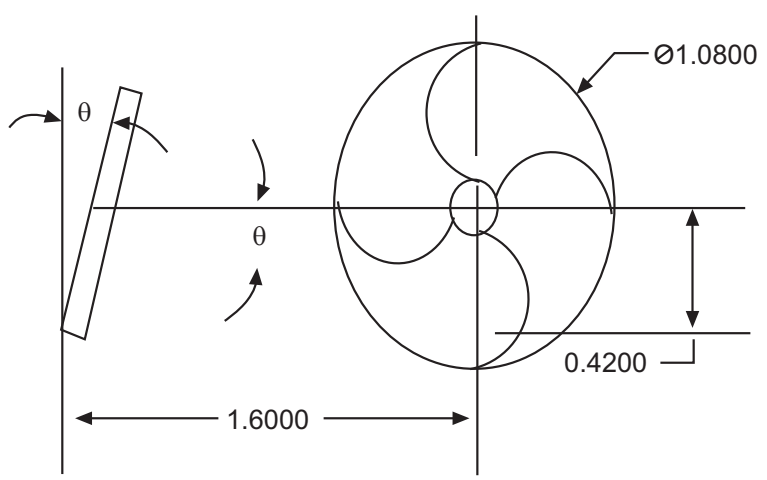

Fig. 3. Top view of the rotor and wind source.

rotor speed at various positions and changing orientation was detected as shown in Fig. 4 (a-b).

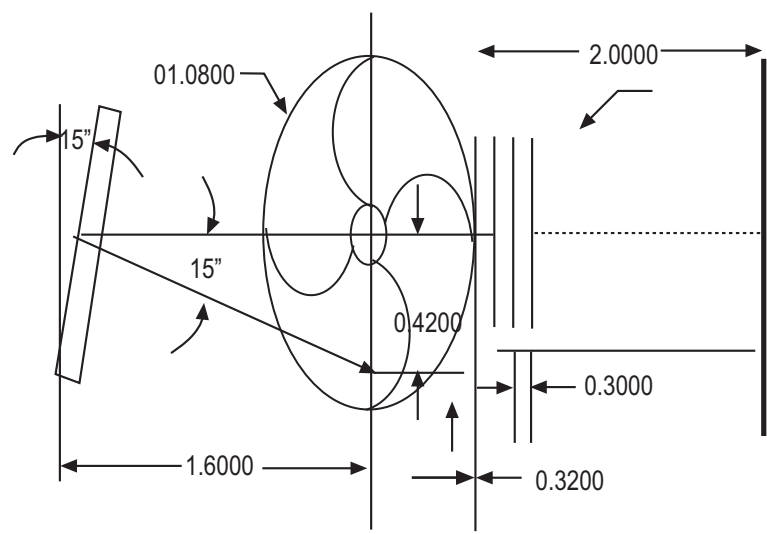

Fig. 4a. 2D view of rotor at various positions of flat wall.

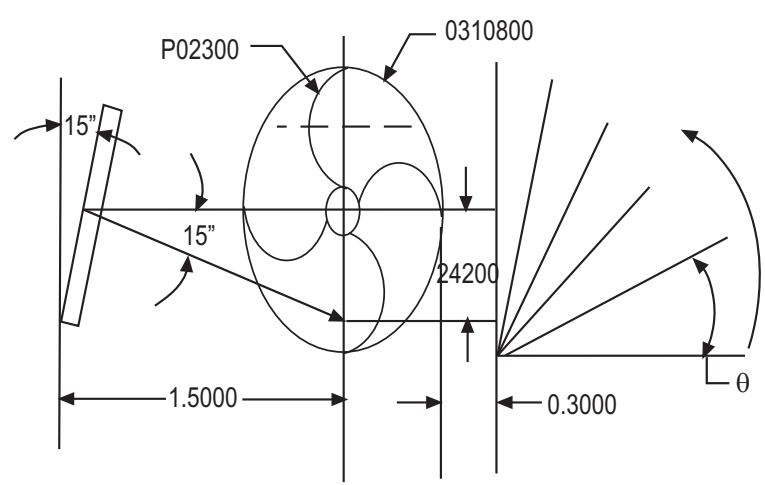

Fig. 4b. 2D view of rotor at changing orientation of flat wall.

Semi-circular wall blockage. The curved wall was used to divert downstream wind flow in order to observe diversion effects on the rotor performance. In this set up a semicircular vertical wall of radius $0.84 \mathrm{~m}(0.3 \mathrm{~m}$ greater than the radius of rotor) was placed vertically to cover half of the rotor from downstream side. Tests were conducted with the clockwise rotation of wall at every $10^{\circ}$ rotation with horizontal axis of rotor. The tangents drawn at each rotation step intersect the effective path of wind and create its new path after diversion as shown in Fig. 5.

Cylindrical wall blockage. The semi-circular vertical wall blockage discussed in previous section was enhanced from two to three quadrants. Here, in this case only wind beam direction side quadrant was left open to intake wind from tunnel. It seems to be a cylindrical enclosure for vertical axis wind turbine with horizontal opening for inward wind flow and vertical opening for outward flow as shown in Fig. 6. The geometry with all defined dimensions was tested as an outward wind flow blocker and direction diverter to study its effects on the performance of the rotor. 


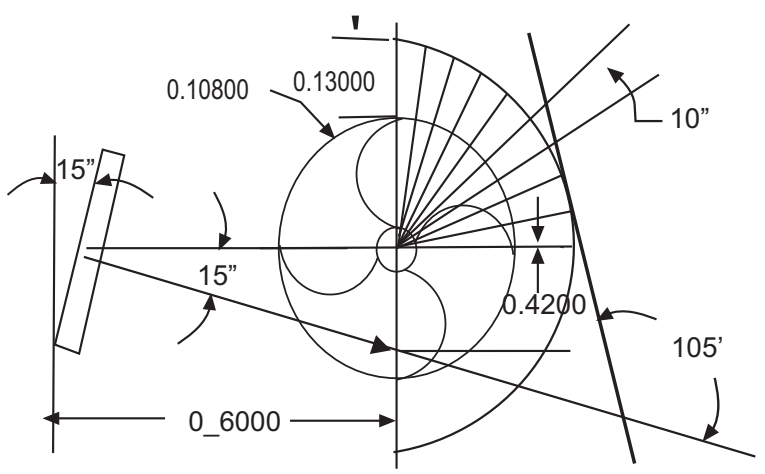

Fig. 5. 2D view of the semi circular vertical wall rotor.

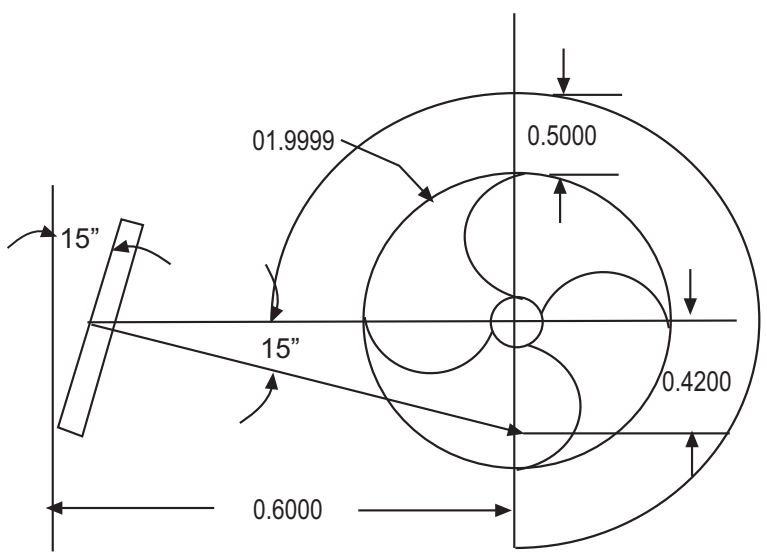

Fig. 6. 2D view of the cylindrical blockage rotor.

\section{Results and Discussion}

Performance of VAWT at various source wind directions. The performance of vertical axis wind turbine (VAWT) rotor in terms of rpm was tested at various speeds of wind source by changing direction of the wind beam striking from centre of the rotor to the tip of the rotor active side without introducing blockage in the downstream flow (free stream wind). Effect of the rotation of wind source on the rotor speed is shown in Fig. 7. It was observed that $15^{\circ}$ clockwise rotation of wind source for this particular rotor was most effective. This new path of the wind mostly fits with the geometry of the blades of the selected rotor.

In the second proposed setup, wind tunnel was adjusted at specified wind direction. The effect of wind velocity on the performance of the rotor was analysed. It was observed that rotor speed increases approximately in linear way with velocity. It may be noted that the small variation in performance was observed due to natural wind interference in the path of effective wind direction. Effect of the wind velocity on rotor speed is shown in Fig. 8.
Performance of VAWT with flow diverters. Flat wall. The effect of flat wall blockage at downstream side was analysed initially by varying the distance between wall and the rotor placed normally as shown in Fig. 9. Maintaining the necessary clearance between wall and rotor blade, first test data was taken at a distance of $0.02 \mathrm{~m}$ from the rotor blade. Other tests were conducted at constant distance variation of $0.3 \mathrm{~m}$.

From this proposed set up, it was observed that the blockage effect was realised upto $1.7 \mathrm{~m}$. The speed of rotor increases linearly with change in distance between rotor and blockage up to $1.7 \mathrm{~m}$ as shown in Fig. 9. All the readings were taken on effective wind direction.

Similarly, the flat wall was rotated anticlockwise at its position of $1.7 \mathrm{~m}$ from rotor and the effect on the performance of vertical axis wind turbine was observed at various rotation angles as shown in Fig. 10. It was observed that performance of the rotor decreases with

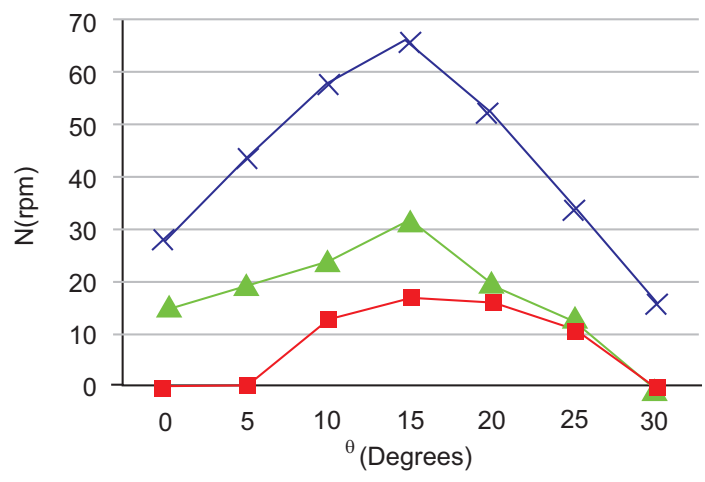

$N(V=1 \mathrm{~m} / \mathrm{s}),-N(V=3 \mathrm{~m} / \mathrm{s}), * N(V=5 \mathrm{~m} / \mathrm{s})$

Fig. 7. Effect of wind direction change on rotor performance.

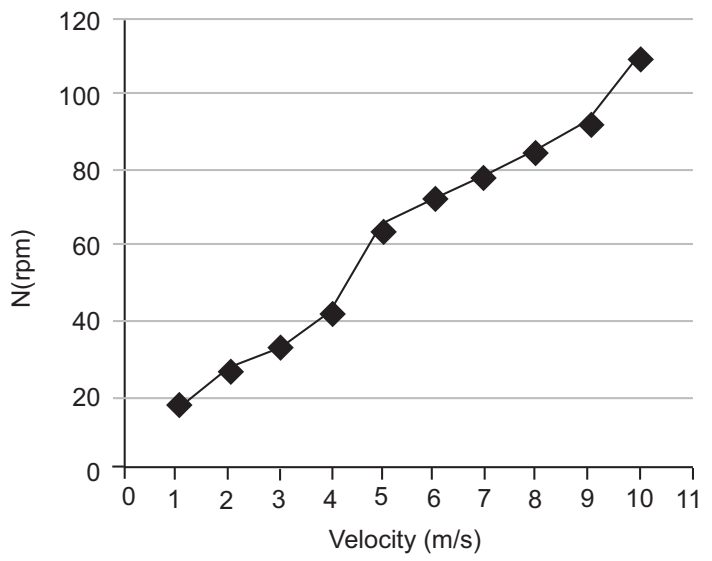

Fig. 8. Effect of wind speed on rotor speed. 


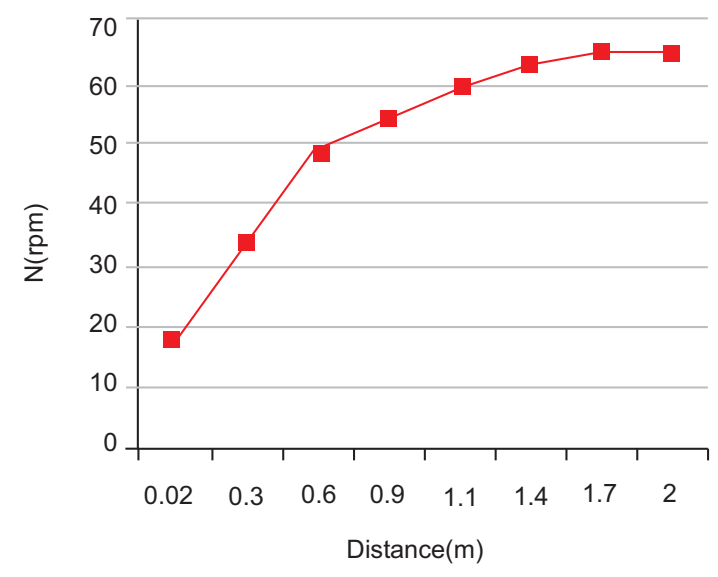

Fig. 9. Effect of change in displacement of the wall blockage on rotor speed.

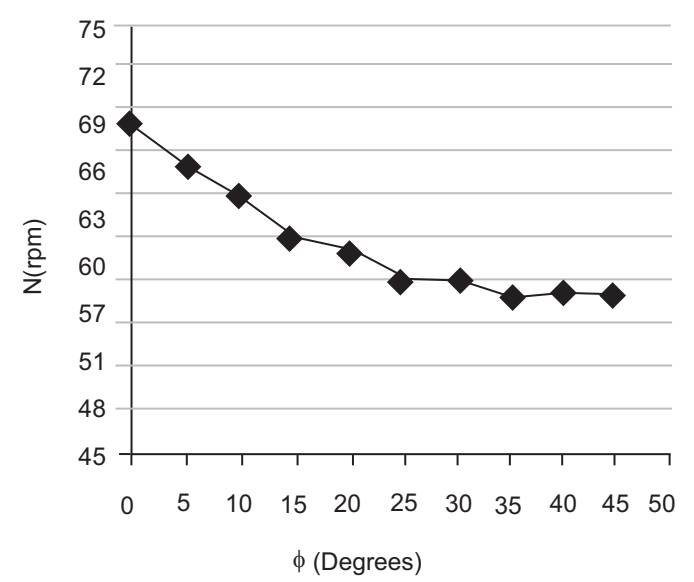

Fig. 10. Effect of flat wall rotation on the rotor speed.

increase in the rotation angle from $0^{\circ}$ to $90^{\circ}$ in response to increase blockage. The maximum reduction in its speed was about $20 \%$.

Semi-circular vertical wall. In this set up semi-circular wall was used as a blocker of downstream wind flow to divert the wind after leaving the rotor. From this experimental set up it was observed that performance of the rotor in terms of the speed increases linearly with change in wind velocity. Effect of the semi-circular blockage on the speed of the rotor is shown in Fig. 11.

Simultaneously, semi-circular wall was rotated and observations were recorded at every $10^{\circ}$ rotation angle as shown in Fig. 12. It is obvious from the figure that $15 \%$ improvement in the performance of rotor speed was recorded at $70^{\circ}$ rotation angle and then it returns to its free stream performance of $66 \mathrm{rpm}$ with further rotations. This $70^{\circ}$ rotation angle diverts flow at about $105^{\circ}$ rotation angle in the direction of rotor.

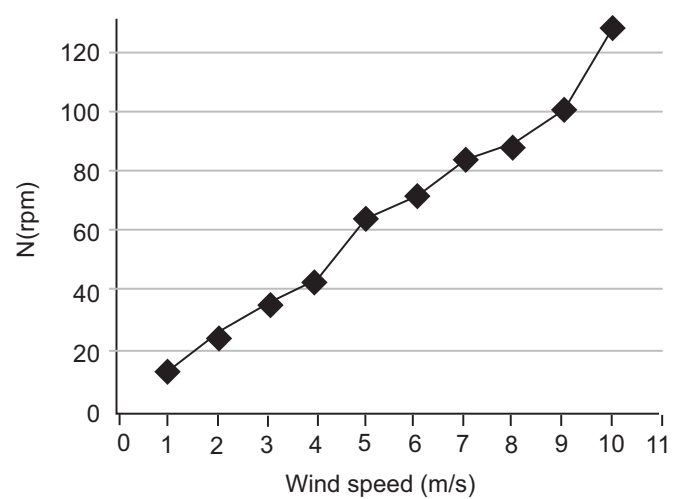

Fig. 11. Effect of semi circular wall blockage on rotor speed.

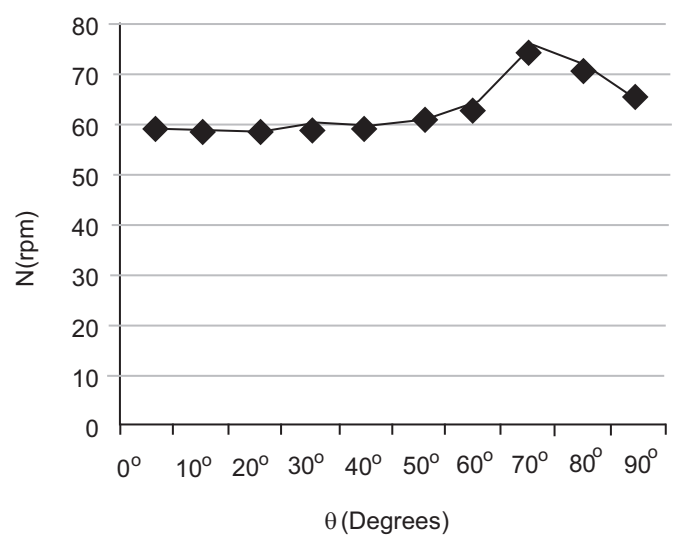

Fig. 12. Effect of semi circular wall clockwise rotation on the rotor speed.

Cylindrical wall. In this experimental set up, a cylindrical wall blockage system was proposed for downstream wind flow and tests were conducted at source wind direction normal to the vertical axis of the rotor. The performance was tested by increasing source wind velocity from 0 to $10 \mathrm{~m} / \mathrm{s}$ as shown in Fig. 13. It was recorded that rotor speed decreases up to $45 \%$ as compared to free stream conventional rotor speed. Simultaneously, this proposed blockage set up was tested by changing the source wind direction and was observed that $15^{\circ}$ rotation of source gives $65 \mathrm{rpm}$ as shown in Fig. 14.

From this research study, it has been analysed that the bluff bodies with the changing in their orientation took aerodynamic characteristics and could improve the performance of VAWT when placed at the downstream side of turbine.

The performance of rotor speed with and without flow diverting geometries at source wind speed of $5 \mathrm{~m} / \mathrm{s}$ and source wind angle $(\theta)$ of $15^{\circ}$ are shown in Table 1 . Here $\varphi$ is rotation angle of various types of tested blockages. 


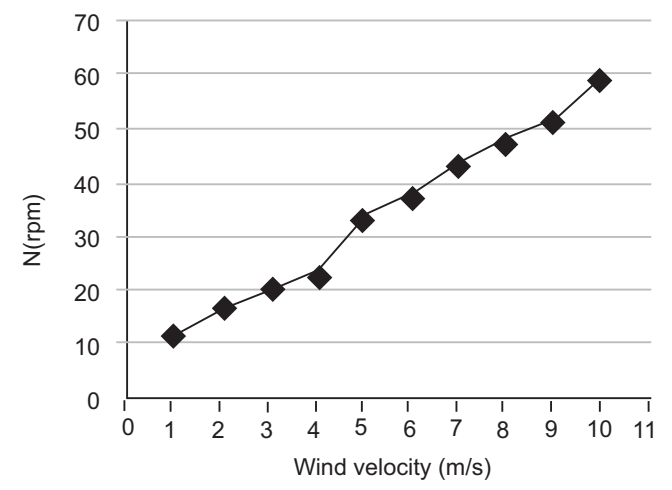

Fig. 13. Effect of the cylindrical blockage on the rotor speed.

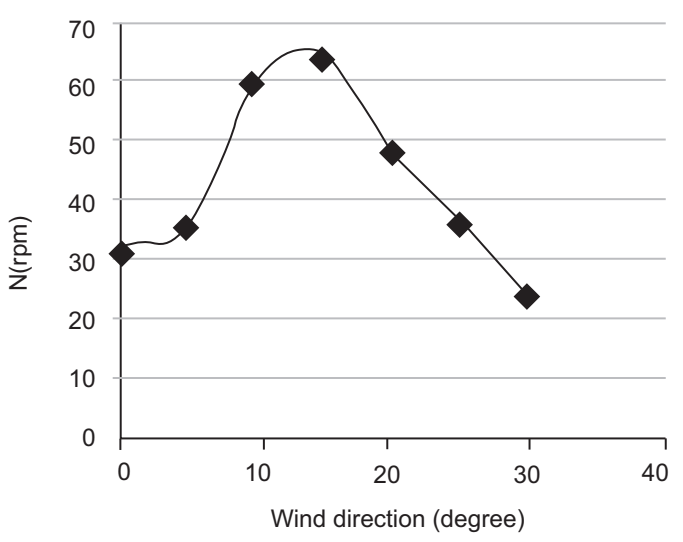

Fig. 14. Effect of change of angle of attack $(\theta)$ on the rotor speed during cylindrical blockage.

Table 1. Performance of rotor at various blockage rotations.

\begin{tabular}{|c|c|c|c|c|c|}
\hline \multirow{3}{*}{ Rotor } & \multicolumn{4}{|c|}{ Type of blockage } & \multirow{3}{*}{ Cylindrical wall } \\
\hline & \multicolumn{2}{|c|}{ Flat wall } & \multicolumn{2}{|c|}{ Curved wall } & \\
\hline & $(\min )$ & $(\max )$ & (Min) & (Max) & \\
\hline Rotation & & & & & \\
\hline angle $\left(\varphi_{2}\right)$ & $0^{\circ}$ & $90^{\circ}$ & $0^{\circ}$ & $70^{\circ}$ & (No rotation) \\
\hline $\begin{array}{l}\text { Rotor speed } \\
(\mathrm{rpm})\end{array}$ & 67 & 54 & 60 & 71 & 64 \\
\hline
\end{tabular}

Overall performance of the rotor speed at various proposed blockages of downstream wind flow is shown in Fig. 15. It has been observed that curved wall blockage of downstream flow gave batter performance of $71 \mathrm{rpm}$ of motor as compared to flat wall blockage of $67 \mathrm{rpm}$ as shown in Fig. 15.

\section{Conclusion}

- The downstream flow path diversion with flat wall shows batter blockage effect (generate back pressure

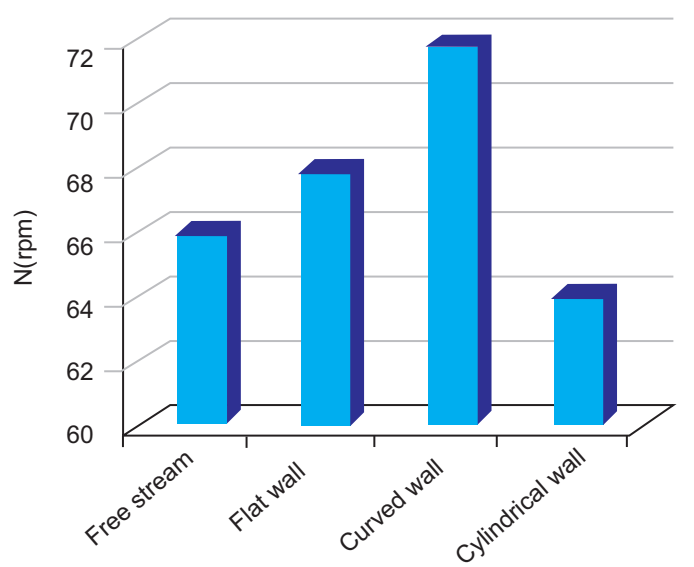

Fig. 15. Performace of rotor speed at various types of blockage.

with turbulence) at $90^{\circ}$ angle of attack and redevelops stream line flow at zero degree angle of attack. Smaller angles can be used for flow diversion with minimum loss, if necessarily required.

- Semi-circular vertical wall flow diverter redirects and guides flow in the direction of projected area of rotor and extract $15 \%$ more wind energy as compared to conventional wind turbine without downstream wind flow blockages.

- In semi-circular (curved) wall blockage system maximum rotor speed of $71 \mathrm{rpm}$ ( $40 \%$ improved) was observed at $105^{\circ}$ diversion angle at $5 \mathrm{~m} / \mathrm{s}$ source wind speed and $15^{\circ}$ degree of source wind direction towards rotor projected area.

- The cylindrical type of proposed blockage of downstream wind flow, decreases rotor speed up to $40 \%$ when source wind is striking at normal to projected area of rotor. When source wind direction was rotated clockwise at an angle of $15^{\circ}$ from rotor axis, the loss of the rotor performance in terms of speed can be recovered.

- This research study is applicable only for proposed four bladed rotors with known parameters.

Recommendations. These flow path diverting geometries may be used with VAWTs in urban applications to avoid turbulence generated by adjacent buildings at downstream wind flow in order to improve their performance.

\section{Acknowledgement}

The authors acknowledge and appreciate cooperation and technical help provided by Mr. Akhtar Hussain Mughul, Workshop Superintendent, Mechanical Engineering 
Department workshop QUEST, Nawabshah and his staff in the development of this project.

\section{References}

Abe, K., Nishida, M., Sakurai, A., Ohya,Y., Kihara, H., Wada, E., Sato, K. 2005. Experimental and numerical investigations of flow fields behind a small wind turbine with a flanged diffuser. Journal of Wind Engineering and Industrial Aerodynamics, 93: 951970.

Bussel, G.J.W.V. 2007. The science of making more torque from wind. Journal of Physics, 75: 1-13.

Chong, W.T., Poh, S.C., Fazlizan, A., Pan, K.C. 2012. Vertical axis wind turbine with Omni-directionalguide-vane for urban high-rise buildings. Journal of Central South University, 19: 727-732.

Chong, W.T., Poh, S.C., Abdullah, A.F., Oon, C.S., Tiah, C.C. 2011.Exhaust air and wind energy recovery system for clean energy generation. International Conference on Environment and Industrial Innovation, IACSIT Press, pp. 45-49, Kuala Lumpur, Malaysia.

Chong, W.T., Mansor, S., Omar, W.Z.W., Pan, K.C., Deep, C.H. 2009. Design features and requirements of an innovative 3-in-1 wind-solar hybrid renewable energy and rain water harvester for urban high rise application. In: Proceeding of $3^{\text {rd }}$ International Conference on Sustainable Energy and Environment, pp. 264-251, Bangkok, Thailand.

Dhanasekaran, T.S., Govardhan, M. 2005. Computational analysis of performance and flow investigation on wells turbine for wave energy conversion. Renewable Energy, 30: 2129-2147.

Grant, C.J., Kelly, N. 2008. Urban wind energy conversion. The potential of ducted turbines. Renewable Energy, 33: 1157-1163.

Grassmann, H., Bet, F., Cabras, G., Ceschia, M., Cobai, D., Delpapa, C. 2003. A partially static turbine- first experimental results. Renewable Energy, 28: 1779-1785.

Hu, S.Y., Cheng, J.H. 2008. Innovatory designs for ducted wind turbines. Renewable Energy, 33: 1491-1498.

Lawn, C.J. 2003. Optimization of the power output from ducted wind turbines. Journal of Power and Energy, 217: 107-117.

Li, X.X., Leung, D.Y.C., Liu, C.H., Lam, K.M., 2008. Physical modeling of flow field inside urban street canyons. Journal of Applied Meteorology and Climatology, 47: 2058-2067.

Lilley, G.M., Rainbird, W.J. 1956. A Preliminary Report on the Design and Performance of a Ducted Windmill. Report 102, College of Aeronautics, Cranfield, U.K.

Lu, L., Ip, K.Y. 2009. Investigation on the feasibility and enhancement methods of wind power utilization in high-rise buildings of Hong Kong. Renewable \& Sustainable Energy Reviews, 13: 450-461.

Oppenheim, D., Owen, C., White, G. 2004. Outside the square integrating wind into urban environments. Refocus, 5: 32-35.

Ssu-Yuan, H., Jung-Ho, C. 2008. Innovatory designs for ducted wind turbines. Renewable Energy, 33: 1491-1498.

Sung-Cheoul, R., Seung-Hee, K. 2013. Effects of a blade profile, the Reynolds number and the solidity on the performance of a straight bladed vertical axis wind turbine. Journal of Mechanical Science and Technology, 27: 3299-3307.

Wang, F., Bai, L., Fletcher, J., Whiteford, J., Cullen, D. 2008. The methodology for aerodynamic study on a small domestic wind turbine with scoop. Journal of Wind Engineering and Industrial Aerodynamics, 96: $1-24$.

Webb. A. 2007. The Viability of Domestic Wind Turbines for Urban Melbourne. Report prepared for Alternative Technology Association, Australia, 61 pp. 